This item was submitted to Loughborough's Research Repository by the author.

Items in Figshare are protected by copyright, with all rights reserved, unless otherwise indicated.

\title{
Factors affecting knowledge sharing in the virtual organisation: employees' sense of well-being as a mediating effect
}

PLEASE CITE THE PUBLISHED VERSION

http://dx.doi.org/10.1016/j.chb.2014.11.040

\section{PUBLISHER}

(c) Elsevier Ltd

VERSION

AM (Accepted Manuscript)

\section{PUBLISHER STATEMENT}

This work is made available according to the conditions of the Creative Commons Attribution-NonCommercialNoDerivatives 4.0 International (CC BY-NC-ND 4.0) licence. Full details of this licence are available at: https://creativecommons.org/licenses/by-nc-nd/4.0/

\section{LICENCE}

CC BY-NC-ND 4.0

\section{REPOSITORY RECORD}

Chumg, Hao-Fan, Louise Cooke, Jenny Fry, and I-Hua Hung. 2019. "Factors Affecting Knowledge Sharing in the Virtual Organisation: Employees' Sense of Well-being as a Mediating Effect". figshare. https://hdl.handle.net/2134/16854. 


\title{
Factors affecting knowledge sharing in the virtual organisation: Employees' sense of well-being as a mediating effect
}

\begin{abstract}
In view of the importance of employees' knowledge sharing, this research, which draws on social capital theory and employees' sense of well-being, develops a comprehensive theoretical model which aims to explore deeply the mediating impact of employees' sense of well-being on social capital and the contribution of knowledge in the complex context of a virtual organisation. The quantitative approach was conducted at a virtual organisation of Taiwanese NGOs. 135 valid questionnaires were distributed and retrieved personally; subsequently these were analysed using partial least squares (PLS). The findings revealed that employees' sense of well-being improved considerably when they demonstrated stronger levels of social capital tendency. Meanwhile, employees increasingly contributed, not only their tacit but also their explicit knowledge, when they experienced a greater sense of well-being. Even more surprisingly, the results showed that employees' sense of well-being played a positively and pivotally mediating role in the relationship between social capital and employees' tacit and explicit knowledge-sharing behaviour in the virtual organisation. These suggest that managers within virtual organisations urgently need strategies to create an ambiance in which employees can feel a sense of well-being in order to enhance their willingness to share both their explicit and tacit knowledge.
\end{abstract}

Keywords: Knowledge-sharing Behaviour, Social Capital, Sense of Well-being, Partial Least Squares (PLS)

\section{Introduction}

Considering the importance of employees' knowledge sharing (Zhang, de Pablos, \& Zhou, 2013), together with the ever-accelerating expansion of Information and Communication Technologies (ICTs), an increasing number of organisations are gradually changing their knowledge management and operating modes, moving from conventional face-to-face relationships to virtual ones. Many such organisations have begun to adopt the concept of the virtual organisation owing to the fact that such an organisation consists of companies whose employees have the characteristics of working cooperatively, coordinating flexibly and organising dynamically in order to reflect business requirements (Goldman, Nagel, \& Preiss, 1995). Prior research studies have validated that knowledge-sharing behaviour is strongly associated with social incentives (Chow \& Chen, 2008; Zhang, de Pablos, \& Zhang, 2012) and 
personal intrinsic motivation (Wasko \& Faraj, 2005). Yet, the reasons and motives for exchanging and sharing knowledge among employees in a virtual organisation seem more complex and difficult to comprehend as compared with those in an independent organisation (Alge, Wiethoff, \& Klein, 2003). For instance, one major concern is that social relationships among employees in a virtual organisation may be a critical factor prohibiting their knowledge-sharing behaviour because of their short-term nature (Zhang, de Pablos, \& Xu, 2014).

Recently, rather than considering negative psychology, an often overlooked yet pivotal element in positive psychology, the sense of well-being, has gradually emerged and been explored in western countries (Seligman \& Csikszentmihalyi, 2000). A wealth of research has suggested that individuals with a greater sense of well-being and satisfaction are correspondingly more successful in an organisation (Boehm \& Lyubomirsky, 2008). For some instances, the sense of well-being has been shown to be strongly related to helping co-workers (George, 1991), offering social support to colleagues (Iverson, Olekalns \& Erwin, 1998), and to income (Diener \& Biswas-Diener, 2002). Most researchers have assumed that such indicators of success in the workplace are the result of individuals being happy (Boehm \& Lyubomirsky, 2008). However, no research seems to have explored in detail whether employees' sense of well-being can lead to knowledge-sharing and the increased success of an organisation. This may be an oversight as a sense of well-being in individuals elicits positive behaviour such as knowledge-sharing. Furthermore, the alternative hypothesis posited by this study, that employees' sense of well-being plays a critical mediating role in the relationship between social capital and employees' both tacit and explicit knowledge-sharing behaviour, may be equally plausible.

This research aims to investigate employees' knowledge-sharing behaviour in the virtual organisation of Taiwanese NGOs. In fact, with the accelerating sense of social democracy in Taiwan and the nation's continuous economic development, a considerable number of social organisations, such as Non-Governmental Organisations (NGOs), have proliferated with a view to providing a range of social welfare services in order to make up for deficiencies in the public welfare provided by the Taiwanese government. According to statistical data from the Department of Statistics, Ministry of the Interior, Republic of China (Taiwan) in 2013, 40,316 NGOs have been established in Taiwan. However, Drucker (1990) states that, unlike For-Profit Organisations, Non-Profit Organisations (NPOs) need to be managed more effectively. Chi, Yeh and Yu (2008) further suggest that NGOs often lack knowledge of management and that this can hinder their organisational development. Having 
considering this lack of development in Taiwanese NGOs and the importance of knowledge sharing, this research, drawing on social capital theory and the sense of well-being, focuses mainly on investigating the willingness of employees to share their knowledge in the whole system of Farmers' Associations which is categorised as a virtual organisation. Consequently, the particular objectives of this research are to: (1) investigate the relationship between social capital and employees' sense of well-being within the virtual organisation; (2) explore the role of employees' sense of well-being in their knowledge sharing in the context of the virtual organisation; (3) understand the correlation between tacit and explicit knowledge sharing in the virtual organisation. These proposed objectives help in answering four research questions: (1) How can social capital explain employees' sense of well-being? (2) How can employees' sense of well-being facilitate their knowledge sharing in the virtual organisation? (3) How can employees' sense of well-being mediate in the relationship between social capital and knowledge sharing in the virtual organisation? (4) How can employees' tacit knowledge sharing facilitate their explicit knowledge sharing in the virtual organisation?

\section{Theoretical Background}

\subsection{Social Capital Tendency}

The concept of social capital mentioned by Jane Jacobs (1965) has been widely used over the past few decades to explore the sociological domain. Bourdieu (1986) states that social capital is a term for the collective unit by which collective members obtain actual or potential resources and effectively mobilise their own group; through social capital, a durable network is formed. Later, the comprehensive understanding of the theoretical dimensions of social capital outlined by Nahapiet and Ghoshal (1998) suggests that the theory consists of structural, cognitive and relational dimensions; these explore members' interpersonal relationships and organisational phenomena. Nowadays, researchers widely apply social capital theory to investigate and comprehend the organisational phenomena and interpersonal relationships associated with knowledge sharing and organisational performance in the domain of Management Information Systems (MIS), particularly knowledge management (e.g., Chow \& Chan, 2008; Hau, Kim, Lee, \& Kim, 2013; He, Qiao, \& Wei, 2009; Nahapiet \& Ghoshal, 1998; Wasko \& Faraj, 2005). In the meantime, the majority of research studies have posited that social network ties, shared goals and trust are the major constructs corresponding to structural capital, cognitive capital and relational capital respectively for exploring individuals' willingness to share knowledge in 
organisations (Chow \& Chan, 2008; Hau et al., 2013; He et al., 2009). Hence, based on the above-mentioned perspectives and the theoretical development of this research, this study chose to adopt, as its research model, shared goals, trust and social network ties corresponding to cognitive capital, relational capital and structural capital respectively.

\subsection{Employees' Sense of Well-being}

Positive psychology in terms of well-being has been discussed a great deal in western countries, in particular focusing on senior citizens and adolescents. This growing number of researchers has gradually divided into two camps considering different yet related perspectives or factors: namely, hedonism and eudemonism (Ryan \& Deci, 2001). Table 1, integrated by this study, shows relevant literature revolving around the sense of well-being.

\section{Table 1}

Relevant Literature Concerning the Sense of Well-being Integrated in this Study

\begin{tabular}{|c|c|}
\hline & finition \\
\hline $\begin{array}{l}\text { Diener, Suh, } \\
\text { Lucas and } \\
\text { Smith (1999) }\end{array}$ & $\begin{array}{l}\text { Subjective well-being can be viewed as a broad category of phenomena } \\
\text { that consists of individuals' emotional responses and domain } \\
\text { satisfactions, as well as global judgments of life satisfaction. }\end{array}$ \\
\hline $\begin{array}{l}\text { Diener, Lucas, } \\
\text { and } \\
\text { (2002) }\end{array}$ & $\begin{array}{l}\text { Subjective well-being is a broad concept which encompasses greater life } \\
\text { satisfaction plus higher pleasant emotion and lower levels of negative } \\
\text { emotion. }\end{array}$ \\
\hline $\begin{array}{l}\text { Diener anc } \\
\text { Seligman } \\
(2004)\end{array}$ & $\begin{array}{l}\text { e sense of well-being is defined as an individual's positive evaluations } \\
\text { his/her live, including positive emotions, engagement, satisfaction and } \\
\text { aning. }\end{array}$ \\
\hline $\begin{array}{l}\text { Dodge, Daly, } \\
\text { Huyton and } \\
\text { Sanders (2012) }\end{array}$ & $\begin{array}{l}\text { The sense of well-being is regarded as a state of equilibrium which is } \\
\text { affected by life events or challenges. }\end{array}$ \\
\hline $\begin{array}{l}\text { Kahneman and } \\
\text { Riis (2005) }\end{array}$ & $\begin{array}{l}\text { The sense of well-being is seen as being a hybrid concept encompassing } \\
\text { two components: experienced well-being and evaluated well-being. Both } \\
\text { are subjective and intertwined and refer to a period of time. Experienced } \\
\text { well-being covers the statistics of the momentary affective states } \\
\text { experienced during the period, while evaluated well-being embodies } \\
\text { global subjective evaluations of the individual's life during the same } \\
\text { period. }\end{array}$ \\
\hline
\end{tabular}

Ryan and Deci Well-being is viewed as a complicated construct involving optimal 
(2001)

Subjective well-being shot

Russell (2008) Subjective well-being should consist of emotional well-being (satisfaction with life and the balance of positive to negative effects) and positive functioning (psychological well-being plus social well-being).

With regard to the concept of subjective well-being, Russell (2008) states that this concerns individuals' perspectives of their life experiences, including an affective and cognitive appraisal of their lives. Ryan and Deci (2001) clarify that subjective well-being can be a sensation which combines and is appraised in terms of three dimensions. These are: 1) satisfaction, 2) positive factors, and 3) negative aspects. Thus, individuals might have a greater sense of well-being when they demonstrate higher levels of positive emotions and life satisfaction, together with lower levels of negative aspects (Diener et al. 2002). Likewise, an individual possessing positive emotional characteristics was likely to increase his/her satisfaction with life (Cohn, Fredrickson, Brown, Mikels, \& Conway, 2009). Schwarz and Clore (2007) suggested that individuals depended on their emotional experiences to evaluate their satisfaction with life. Hence, individuals' satisfaction with their lives is equally and highly associated with the existence of positive emotions and the absence of negative ones. Meanwhile, the job and life satisfaction of an individual are highly correlated and inter-related (Saari \& Judge, 2004). Since an individual's job plays an important role in his/her life, job satisfaction may spill over into life satisfaction or vice versa (Saari \& Judge, 2004). Consequently, in view of various instruments and the complex abstract concept of an individual's sense of well-being, this research adopted the Oxford Happiness Questionnaire Short-Form (OHQ) developed by Hills and Argyle (2002) in relation to the scale for psychological well-being. The main reason for this was that the Oxford Happiness Questionnaire (OHQ) stemmed from the Oxford Happiness Inventory (Argyle, Martin, \& Crossland, 1989) developed by Hills and Argyle (2002). This has been widely commended for its robust construct validity and sustainable positive correlation with the measures of self-esteem, extraversion, satisfaction with life, the life regard index, the depression-happiness scale and $\mathrm{OHI}$ (Hills \& Argyle, 2002; Joseph \& Lewis; 1998; Robbins, Francis, \& Edwards, 2010).

\subsection{Tacit and Explicit Knowledge-sharing Behaviour}

Nonaka (1994) and Nonaka and Takeuchi (1995), who put forward the SECI model, explain the generation, creation and transfer of knowledge, which can be classified into four modes: socialisation, externalisation, combination and internalisation, moving between tacit and explicit knowledge. In this model, the explicit knowledge 
of an individual can be articulated by him/herself so that this type of knowledge can be written down, taped or made into a tangible form (Reychav \& Weisberg, 2009). Meanwhile, an individual's contribution to tacit knowledge is widely viewed as a critical element of improving organisational competitive advantage (Reychav \& Weisberg, 2009). Fundamentally, tacit knowledge appertains to highly personalised knowledge which is difficult to formalise or write down (Nonaka, 1991). Hau et al. (2013) further consider that individuals' explicit knowledge requires less effort to share as compared with their tacit knowledge. An individual who has the willingness to share tacit knowledge, undoubtedly shares his/her explicit knowledge (Hau et al., 2013). Dhanaraj, Lyles, Steensma and Tihanyi (2004) validated that tacit knowledge sharing positively influences explicit knowledge sharing while Reychav and Weisberg (2009) demonstrated that individuals who are willing to share their tacit knowledge will also be likely to share their explicit knowledge. Hence, this study speculates that the more tacit knowledge employees share, the more they will share explicit knowledge.

\section{Research Model and Hypotheses}

To understand comprehensively the mediating effect of employees' sense of well-being on the relationship between social capital theory and both their tacit and explicit knowledge-sharing behaviour in the virtual organisation, the conceptual framework, based on social capital and subjective well-being, was designed. This was followed by the hypotheses which are postulated with a view to completing the aims of this study. Fig. 1 and Table 2 below represent the theoretical model and operational definitions of the constructs of this research respectively.

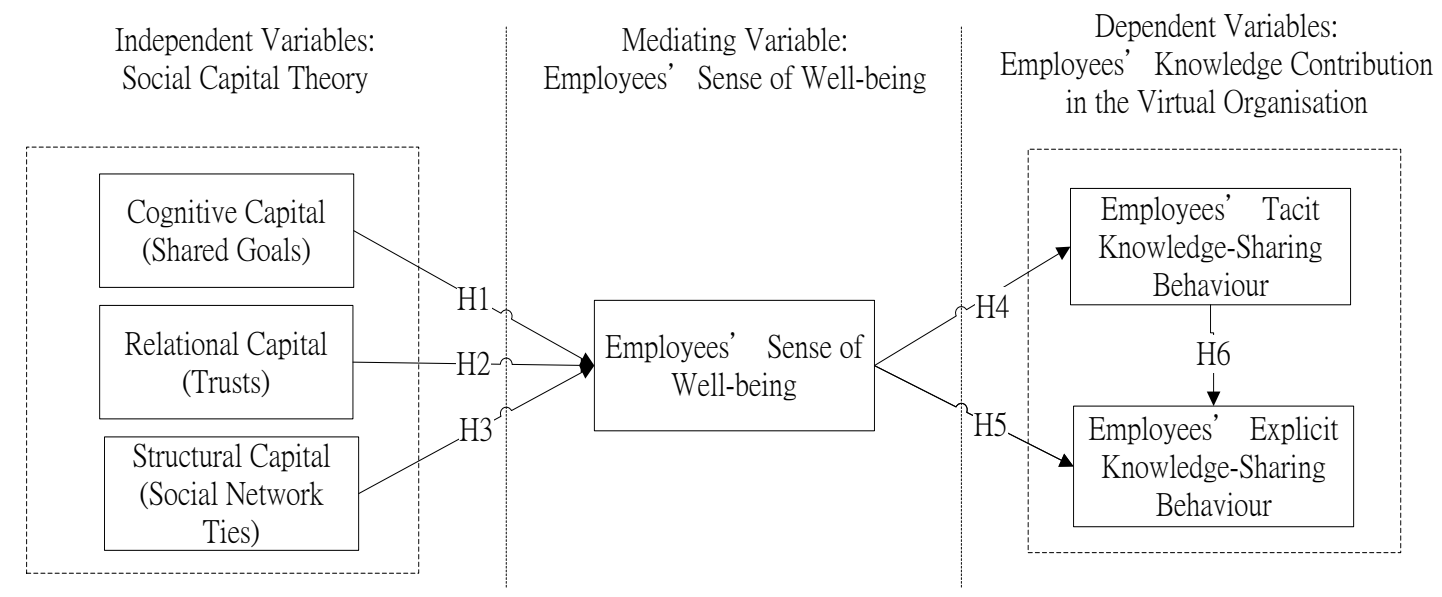

Fig. 1. Research Model 
Table 2

Operationalisation of Constructs

\begin{tabular}{|c|c|c|}
\hline Constructs & Operational Definition & Source \\
\hline $\begin{array}{l}\text { Shared } \\
\text { Goals } \\
\text { (Cognitive } \\
\text { Capital) }\end{array}$ & $\begin{array}{l}\text { The presences of shared goals can enhance mutual } \\
\text { understanding and the exchange of ideas among } \\
\text { colleagues, bind a variety and number of them } \\
\text { together, and encourage them to contribute their } \\
\text { knowledge. }\end{array}$ & $\begin{array}{l}\text { Chow and Chan } \\
\text { (2008), Chiu, Hsu } \\
\text { and Wang (2006) }\end{array}$ \\
\hline $\begin{array}{l}\text { Trust } \\
\text { (Relational } \\
\text { Capital) }\end{array}$ & $\begin{array}{l}\text { Trust, which is a key facet of the relational capital of } \\
\text { social capital, improves compact interactions } \\
\text { between employees in virtual organisations. }\end{array}$ & $\begin{array}{l}\text { Chiu et al. (2006) } \\
\text { Chow and Chan } \\
\text { (2008), He et al } \\
\text { (2009) }\end{array}$ \\
\hline $\begin{array}{l}\text { Social } \\
\text { Network } \\
\text { Ties } \\
\text { (Structural } \\
\text { Capital) }\end{array}$ & $\begin{array}{l}\text { Social networks, based on the structural capital of } \\
\text { social capital, promote more opportunities for } \\
\text { employees of a virtual organisation to make } \\
\text { interpersonal contacts. }\end{array}$ & $\begin{array}{l}\text { Chow and Chan } \\
\text { (2008), He et al } \\
\text { (2009) }\end{array}$ \\
\hline $\begin{array}{l}\text { Employees' } \\
\text { Sense of } \\
\text { Well-being }\end{array}$ & $\begin{array}{l}\text { An individual's sense of well-being is a state of mind, } \\
\text { which is constructed through a complex, contextual } \\
\text { and meaningful sentiment. It comes not merely from } \\
\text { private emotions, such as pleasure, displeasure, } \\
\text { satisfaction with life and so forth, but also from } \\
\text { experiencing various social challenges. Meanwhile, } \\
\text { job-related well-being may spill over into life-related } \\
\text { well-being or vice versa. }\end{array}$ & $\begin{array}{l}\text { Keyes (1998) } \\
\text { Russell (2008) } \\
\text { Ryan and Dec } \\
\text { (2001), Saari and } \\
\text { Judge (2004) }\end{array}$ \\
\hline $\begin{array}{l}\text { Tacit } \\
\text { Knowledge } \\
\text { Sharing }\end{array}$ & $\begin{array}{l}\text { Tacit knowledge, such as ideals, skills, values and } \\
\text { mental models, is usually difficult for employees to } \\
\text { express and share with others. }\end{array}$ & $\begin{array}{l}\text { Endres, Endres, } \\
\text { Chowdhury and } \\
\text { Alam (2007) } \\
\text { Holste and Fields } \\
\text { (2010), Nonaka and } \\
\text { Krog (2009) }\end{array}$ \\
\hline $\begin{array}{l}\text { Explicit } \\
\text { Knowledge } \\
\text { Sharing }\end{array}$ & $\begin{array}{l}\text { Employees' explicit knowledge can be effortlessly } \\
\text { captured, codified and written in the form of } \\
\text { technical or academic data and presented in such } \\
\text { forms as journals, manuals, documents and patents. }\end{array}$ & $\begin{array}{l}\text { Nonaka and Krog } \\
\text { (2009), Nonaka and } \\
\text { Takeuchi (1995) }\end{array}$ \\
\hline
\end{tabular}

\subsection{Social Capital Tendency and Employees' Sense of Well-being}


An increasing number of researchers have paid attention to investigating the relationship between an individual's sense of well-being and social capital (Lau \& $\mathrm{Li}$, 2011; Sarracino, 2010; Yamaguchi, 2013). Ryff (1989) highlighted how warm and trusting interpersonal relationships lead to psychological well-being. Later, Ryff and Keyes (1995) and Ryff and Singer (2008) stated that an individual who shows loving care for, and puts his/her trust in interpersonal relationships with others has a greater sense of well-being. Keyes (1998) indicated, based on a socially acceptant view of social well-being, that an individual who has a greater willingness to trust others, thinks that other people have a capacity for kindness, believes that others are industrious, and feels comfortable with them. Diener and Seligman (2004) verified that positive social relationships are pivotal components of well-being and that a sense of well-being leads to satisfying social relationships. Henry (2004) stated that the positive cognitive capital trend of an individual can be conceptualised as an accumulative asset which stems from those aspects of cognitive functioning associated with developing faculties such as memory, attention, perception, problem solving and mental imagery. This is useful in sustaining wellbeing in response to environmental challenges and stress. Meanwhile, an individual who often successfully pursues desired goals will experience a greater sense of well-being (Henry, 2004; Locke \& Lathem, 2006). Later, Locke and Lathem (2006) indicated that higher personal goals that are compatible with the collective goals can effectively enhance collective performance. Thus, the significant and successful shared goals of an organisation are hypothesised to have a greater positive impact on employees' sense of well-being, leading to hypothesis $\boldsymbol{H 1}$.

H1. Greater shared goals among employees positively influence their sense of well-being in the virtual organisation.

An empirical research study carried out by Yip, Subramanian, Mitchell, Lee, Wang and Kawachi (2007) demonstrated that the level of participation in formal associations (namely social network ties) and individuals' mutual trust, based on social capital theory, had a positive impact on an individual's psychological health and an individual's feeling of well-being. Helliwell and Wang (2011) have confirmed that trust is strongly and directly associated with individuals' sense of well-being. Individuals who feel they are situated in a trustworthy environment have greater levels of the sense of wellbeing (Helliwell \& Huang, 2011; Helliwell \& Wang, 2011). Likewise, Helliwell and Putnam (2004) attested that social capital is strongly linked to subjective well-being through many independent channels such as marital status, the level of network ties to friends and neighbours, the degree of civic engagement, 
feeling able to be trustworthy and to trust. Hence, based on the above perspectives from numerous research studies concerning well-being, it is clear that an individual's trend in terms of well-being is strongly associated with his/her social capital. This leads to hypotheses $\boldsymbol{H} \mathbf{2}$ and $\boldsymbol{H} 3$.

H2. A greater sense of trust among employees positively influences their sense of well-being in the virtual organisation.

H3. Stronger social network ties among employees positively influence their sense of well-being in the virtual organisation.

\subsection{Employees’ Sense of Well-being and Knowledge-sharing Behaviour}

An increasing number of research studies has validated that an individual's predisposition towards knowledge sharing can be improved when he/she experiences positive emotions such as enjoyment and delight (Kankanhalli, Tan, \& Wei, 2005; Wasko \& Faraj, 2005). Carr (2004) stated that the fundamental concept of positive psychology encompasses two primary elements: happiness and well-being. According to Diener et al. (2002), the concept of subjective well-being includes positive emotions, negative feelings and satisfaction with life. An individual's feeling of subjective well-being will improve when he/she experiences higher levels of positive emotion and life satisfaction, together with lower levels of negativity (Diener et al., 2002). A growing number of researches have used the concept of well-being to appraise personal cognitive emotion because of its influence on an individual's intention and even behaviour (Blažun, Saranto, \& Rissanen, 2012; Goswami, 2012). Russell (2008) highlights that the higher the level of well-being that employees experience, the better their work performance. Simultaneously, Boehm and Lyubomirsky (2008) assumed that happier employees are more highly likely to be satisfied with their jobs and to take on extra roles or tasks such as helping others. The knowledge-sharing behaviour of employees therefore seems to be considerably driven by their greater sense of well-being. Consequently, this research reasonably postulates that employees' feeling of well-being is not only highly but also positively associated with their knowledge-sharing behaviour in the virtual organisation. This leads to the following hypotheses.

H4. A sense of well-being positively influences employees' tacit knowledge-sharing behaviour in the virtual organisation.

H5. A sense of well-being positively influences employees' explicit knowledge-sharing behaviour in the virtual organisation. 


\subsection{Tacit and Explicit Knowledge-sharing Behaviour}

Nonaka (1994) indicated that the process of the generation and creation of knowledge can be categorised into four types: socialisation, externalisation, combination and internalisation, transferring between tacit and explicit knowledge. The process of externalisation helps create new knowledge as the tacit knowledge of individuals emerges from within its boundary and becomes collective knowledge (Reychav \& Weisberg, 2009). Through this conversion, the tacit knowledge of an individual, therefore, can be captured, codified and written in terms of technical or academic data, as in manuals, documents and patents (Nonaka, 1994). Dhanaraj et al. (2004) also stated that the tacit knowledge of individuals is the transfer of fine-grained information; it offers a meaningful and in-depth understanding of their explicit knowledge. In the light of the difficulties of turning tacit knowledge into explicit knowledge, employees who intend to share tacit knowledge, such as know-how or know-whom, have no reason to be reluctant then to share explicit knowledge such as written documents or files (Hau et al., 2013). Meanwhile, employees’ tacit knowledge, based on the perspective of an organisation, can be perceived as a precious asset that will provide an organisation with a competitive market advantage (Reychav \& Weisberg, 2009). Conversely, from the point of view of employees, their tacit knowledge can be viewed as their own competitive advantage within the organisation (Reychav \& Weisberg, 2009). Hau et al. (2013) also demonstrated that if the employees' intention to share their tacit knowledge is perceived as a valuable resource, this positively influences their intention to share their explicit knowledge. This leads to Hypothesis $\mathbf{H 6}$.

H6. The more employees share their tacit knowledge, the more they will share their explicit knowledge in the virtual organisation.

\section{Research Methodology and Measurement Development}

This research focuses on investigating those factors that affect employees' knowledge-sharing behaviour in the whole system of Farmers' Associations in Taiwan. This whole system, regarded as a virtual organisation of NGOs in this research, consists of three different levels of Taiwanese Farmers' Associations and the National Training Institute for Farmers' Organisations (NTIFO). These three main categories of Taiwanese Farmers' Associations (namely, urban, hybrid and rural) are, according to Huang (1992), significantly separate. Meanwhile, a virtual organisation, as defined by 
this study, consists of a variety of dynamic and temporary organisations whose employees cooperate and coordinate their efforts to pool their facilities and infrastructures, as well as to share skills, competencies, knowledge and resources by utilising Information and Communication Technologies (ICTs), such as E-mail, Knowledge Management Systems (KMS) and video conferencing, in order to pursue a particular goal or market opportunity (Goldman et al., 1995). Finally, three different types of Farmers' Associations in the same administrative region were chosen because this research considered that Farmers' Associations within the same administrative region would be more likely to co-operate and co-ordinate their efforts more easily, frequently and closely. A stratified purposive sampling was adopted to select the respondents for this research and data collection was executed in three stages: first, E-mails, highlighting the importance of the research aims and its contribution to organisations and academia, were sent to Chief Executive Officers (CEOs) of the proposed four companies; this was accompanied by a letter of consent. This stage was imperative in obtaining the support of the CEOs with a view to carrying out the study successfully. Then, a survey questionnaire, which was designed using mixed positively and negatively worded statements concerning the items and a 5-point Likert scale ( 1 = strongly disagree, $5=$ strongly agree) was conducted as a pilot study to evaluate the validity and reliability of the content of the questionnaire. Moreover, two senior supervisors from Loughborough University, two senior professors from the Taiwanese National Chung Hsing University, and one director from NTIFO, all of whom were familiar with the relevant knowledge management domain, were also invited to evaluate the questionnaire in terms of its appropriateness and ease of comprehension in order to prove the instrument's validity. Several items of the questionnaire were then adjusted because the professors considered the wording of these items to be too academic or difficult for respondents to read, while one item concerning organisational culture was removed on account of its sensitivity. After this screening procedure, the final version of the pilot questionnaire contained 28 items. Finally, 43 valid questionnaires were obtained via E-mail from the selected virtual organisation. The measurement model was then evaluated, using Smart-PLS (Version: 2.0.M3), in order to analyse the survey's reliability (both individual item reliability and internal consistency) and validity (i.e. convergent validity and discriminant validity). The analytic results showed that one item regarding relational capital and two items concerning cognitive capital had lower values of factor loading; these were therefore removed from the questionnaire. This apart, the results of the quantitative data showed solid internal consistency reliability, convergent validity and discriminant validity. 


\section{Data Analysis and Results}

\subsection{Descriptive Statistics}

Consequently, the full-scale questionnaire was distributed personally among the respondents who were selected from those working in the Association's affairs, accounting, extension, marketing, credit and insurance departments, in farmers' services, a product market processing plant, and an information office in the chosen virtual organisation. Finally, a total of 135 valid paper questionnaires, from 57 (42.2\%) males and 78 (57.8\%) females in the virtual organisation, were collected over the period from July to September 2013. Table 3 represents the relevant characteristics of the respondents of this research.

\section{Table 3}

Demographic Profile of the Respondents

\begin{tabular}{|c|c|c|c|}
\hline Descriptions & Frequency & Percentage & Cumulative Percent \\
\hline \multicolumn{4}{|c|}{ Information of the virtual } \\
\hline \multirow{2}{*}{\multicolumn{4}{|c|}{$\begin{array}{l}\text { Organisation (The Number } \\
\text { of Respondents) }\end{array}$}} \\
\hline & & & \\
\hline Company 1 (NTIFO) & 38 & 28.1 & 28.1 \\
\hline Company 2 (Urban FA) & 30 & 22.2 & 50.3 \\
\hline Company 3 (Hybrid FA) & 31 & 23.0 & 73.3 \\
\hline Company 4 (Rural FA) & 36 & 26.7 & 100.0 \\
\hline \multicolumn{4}{|l|}{ Gender } \\
\hline Male & 57 & 42.2 & 42.2 \\
\hline Female & 78 & 57.8 & 100.0 \\
\hline \multicolumn{4}{|l|}{ Age } \\
\hline $21 \sim 25$ & 7 & 5.2 & 5.2 \\
\hline $26 \sim 30$ & 11 & 8.1 & 13.3 \\
\hline $31 \sim 35$ & 18 & 13.3 & 26.7 \\
\hline $36 \sim 40$ & 12 & 8.9 & 35.6 \\
\hline $41 \sim 45$ & 25 & 18.5 & 54.1 \\
\hline $46 \sim 50$ & 21 & 15.6 & 69.6 \\
\hline 51 (Over) & 41 & 30.4 & 100.0 \\
\hline \multicolumn{4}{|l|}{ Working Years } \\
\hline 1 (Under) & 11 & 8.1 & 8.1 \\
\hline $1 \sim 3$ & 19 & 14.1 & 22.2 \\
\hline $4 \sim 6$ & 6 & 4.4 & 26.7 \\
\hline
\end{tabular}




$\begin{array}{llll}7 \sim 9 & 5 & 3.7 & 30.4 \\ 10 \sim 15 & 12 & 8.9 & 39.3 \\ 16 \sim 20 & 23 & 17.0 & 56.3 \\ 20 \text { (Over) } & 59 & 43.7 & 100.0\end{array}$

Note 1. FA=Farmers' Association, NTIFO= National Training Institute for Farmers', Organisations.

\subsection{Common Method Variance (bias)}

Meanwhile, in order to avoid the possibility of common method variance (bias) on account of this study using a single source of data, the research adopted a number of methods recommended by Podsakoff, MacKenzie, Lee and Podsakoff (2003) to confirm the quality of the questionnaire. The researcher conducted the quantitative research using mixed positively and negatively worded statements regarding the items, preserving the respondents' anonymity, hiding the name of each research variable, and requiring respondents to answer the questionnaire as honestly as possible. In addition, the research used Harman's single-factor test to evaluate the quantitative data for common method variance. The analytic results showed that the first factor accounted for $42.6 \%$ of the total variance (Podsakoff \& Organ, 1986). This means that no single factor accounts for most of the variance and therefore common method variance was not considered a threat in this research. Besides, the study used Pearson correlation coefficient to measure the correlated degree of each variable. The results represented that the values of the items of each construct are higher than the values of the items of other constructs. This means that each item is highly associated with its variable and that there is no strong correlation between each variable.

\subsection{Procedure for the Analysis of the Quantitative Approach}

Structural Equation Modeling (SEM) using partial least squares (PLS) with Smart PLS (Version: 2.0.M3), was chosen to analyse the proposed hypotheses of this research. PLS is regarded as one of the analytic tools of Structural Equation Modeling (SEM) and is well-designed statistical analytic software for evaluating complicated predictive and multivariate models, including analysis of both the measurement and structural models (Chin, 1998a; Rai, Patnayakuni, \& Seth, 2006). PLS has been widely used in IS research, such as in the work of Wasko and Faraj (2005) and Shao, Feng and Liu, because of its ability to analyse both reflective and formative constructs, and to deal with smaller sample sizes without the requirement to normalise the data (Chin, Marcolin, \& Newsted, 2003). Chin (1998a) suggest that the minimum 
sampling for PLS should be 10 times the maximum number of paths leading into any one construct in the structural equation model. Hence, because the collected sample in this research is relatively small and the purposed relevant theories have limited previous references, the research model was tested using PLS (Version: 2.0.M3).

\subsection{Measurement Model}

The evaluation of the measurement model consists of two main aspects, including tests of the reliability and validity of the instrument items. The reliability test of the measurement model assesses internal consistency, while the test of the validity of the measurement model evaluates both the convergent and discriminant validity of the instrument items (Chin et al., 2003). Basically, composite reliability and Cronbach's Alpha are used to evaluate the internal consistency reliability of each dimension. Concerning the validity of the measurement model, Fornell and Larcker (1981) point out that the value of the average variance extracted (AVE) of each construct of the research is applied to measure convergent validity. Next, with regard to the test for discriminant validity, Fornell and Larcker (1981) indicate that there are two main aspects: the cross-loading matrix and the square root of AVE.

The results of the analysis revealed that the factor loading values for most items were greater than 0.7 and so were significant, except for WB1 and WB2 which had the lower values of factor loading (0.684 and 0.689). These items (WB1 and WB2) were therefore deleted from the measurement model and the researcher retested the measurement model. The analytic results then showed a greater value of factor loading for each item (Barclay, Thompson, \& Higgins, 1995). With regard to the Cronbach Alpha values of each construct evaluated in this research, the values of all constructs were higher than 0.7, ranging in fact from 0.796 to 0.938 (Nunnally, 1978). In this regard, the values of Composite Reliability (CR) for the research constructs exceeded 0.7 in this research, thus achieving an acceptable level of internal consistency (Chin, 1998b; Chin et al., 2003). Subsequently, when assessing the research's convergent validity, which was achieved by checking the Average Variance Extracted (AVE), each construct was found to have exceeded 0.5, ranging in fact from 0.662 to 0.843 (Fornell \& Larcker, 1981). Table 4 represents the relevant values of the measurement model as well as descriptive statistics of the measures (mean, standard deviation, Skewness and kurtosis). Meanwhile, the values of Skewness and kurtosis are acceptable if their values are less than 2.0 and 7.0 respectively (Curran, West, \& Finch, 1996). 


\section{Table 4}

The Relevant Analytic Values of the Measurement Model of the Research (All items are listed in Appendix A)

\begin{tabular}{|c|c|c|c|c|c|c|}
\hline Constructs & Items & Mean (SD) & Loadings & t-Value & Skewness & Kurtosis \\
\hline The Sense of & WB3 & $3.71(0.92)$ & 0.778 & $20.3 * * *$ & -0.35 & -0.42 \\
\hline Alpha=0.896, & WB4 & $3.73(0.83)$ & 0.839 & $31.0 * * *$ & -0.02 & -0.70 \\
\hline \multirow[t]{4}{*}{$\mathrm{CR}=0.921, \mathrm{AVE}=0.662)$} & WB5 & $3.62(0.81)$ & 0.839 & $27.3^{* * *}$ & -0.27 & 0.01 \\
\hline & WB6 & $3.81(0.84)$ & 0.890 & $34.2 * * *$ & -0.30 & -0.45 \\
\hline & WB7 & $3.82(0.88)$ & 0.873 & $44.8 * * *$ & -0.29 & -0.67 \\
\hline & WB8 & $3.39(0.88)$ & 0.795 & $20.5^{* * *}$ & 0.15 & -0.64 \\
\hline Social Network Ties (Cronbach's & SC1 & $3.89(0.71)$ & 0.923 & $61.0 * * *$ & -0.19 & -0.22 \\
\hline Alpha=0.894, & SC2 & $3.87(0.72)$ & 0.941 & $92.9 * * *$ & -0.37 & -0.53 \\
\hline $\mathrm{AVE}=0.826)$ & SC3 & $3.62(0.88)$ & 0.862 & $23.1 * * *$ & -0.21 & -0.64 \\
\hline Shared Goals & CC1 & $3.42(0.90)$ & 0.839 & $28.5^{* * *}$ & 0.05 & -0.47 \\
\hline Alpha=0.796, & CC2 & $3.21(0.91)$ & 0.839 & $26.5^{* * *}$ & -0.08 & -0.43 \\
\hline $\mathrm{AVE}=0.707)$ & CC3 & $3.24(0.86)$ & 0.846 & $15.2^{* * *}$ & 0.14 & -0.04 \\
\hline Trust (Cronbach’s Alpha $=0.852$ & RC1 & $3.59(0.94)$ & 0.861 & $37.0 * * *$ & -0.30 & -0.54 \\
\hline \multirow[t]{2}{*}{$\mathrm{CR}=0.910, \mathrm{AVE}=0.772)$} & RC2 & $3.81(0.97)$ & 0.908 & $50.8 * * *$ & -0.25 & -0.57 \\
\hline & RC3 & $3.82(0.84)$ & 0.866 & $31.4^{* * *}$ & -0.14 & -0.42 \\
\hline Knowledge & TKS1 & $3.37(0.95)$ & 0.928 & $70.4^{* * *}$ & 0.30 & -0.80 \\
\hline Alpha=0.938, & TKS2 & $3.23(0.92)$ & 0.908 & $43.9 * * *$ & 0.10 & -0.44 \\
\hline \multirow[t]{2}{*}{$\mathrm{CR}=0.955, \mathrm{AVE}=0.843)$} & TKS3 & $3.55(0.98)$ & 0.906 & $51.9 * * *$ & -0.08 & -0.78 \\
\hline & TKS4 & $3.22(0.90)$ & 0.932 & $63.4^{* * *}$ & 0.28 & -0.41 \\
\hline Knowledge & EKS1 & $3.66(0.88)$ & 0.922 & $70.0 * * *$ & -0.06 & -0.73 \\
\hline Alpha=0.931, & EKS2 & $3.66(0.86)$ & 0.926 & $69.3 * * *$ & 0.02 & -0.74 \\
\hline \multirow[t]{2}{*}{$\mathrm{CR}=0.951, \mathrm{AVE}=0.830)$} & EKS3 & $3.69(0.89)$ & 0.927 & $66.5^{* * *}$ & 0.08 & -0.93 \\
\hline & EKS4 & $3.35(0.93)$ & 0.869 & $44.3^{* * *}$ & 0.25 & -0.76 \\
\hline
\end{tabular}

Note 1. AVE=Average Variance Extracted, $S D=$ Standard Deviation, $C R=$ Composite Reliability, $W B=$ the Sense of Well-being, SC (Structural capital)=Social Network Ties, CC (Cognitive Capital)=Shared Goals, $R C$ (Relational Capital)=Trust, EKS=Explicit Knowledge Sharing, TKS=Tacit Knowledge Sharing.

Note 2: ${ }^{*} p<0.05 ;{ }^{* *} p<0.01 ;{ }^{* * *} p<0.001$.

The discriminant validity of the measurement model refers to the degree to which the items distinguish between the constructs. This is estimated by two criteria: namely, the square root of the average variance extracted and cross loading. Table 5 below shows that the value of the square root of the average extracted of each latent construct is greater than that construct's correlation with other constructs. According 
to Fornell and Larcker (1981) and Chin et al. (2003), the value of the square root of the average variance extracted of each latent variable can be regarded as acceptable if its value exceeds that construct's correlation with other constructs. In addition, as shown in Table 6, the values of the items of each construct are higher than the values of the items of other constructs; these are therefore acceptable (Fornell \& Larcker, 1981; Chin et al., 2003). Thus, the analytic results reveal that the discriminant validity in this research is strong and the analytic results of the measurement model of this research show good reliability and validity.

\section{Table 5}

The Value of the Square Root of the Average Variance Extracted (AVE) of the Individual Latent Construct

\begin{tabular}{lllllllll}
\hline & Number of Items & Mean/SD & CC & EKS & RC & SC & TKS & WB \\
CC & 3 & $3.29(0.75)$ & $\mathbf{0 . 8 4 0}$ & & & & & \\
EKS & 4 & $3.59(0.81)$ & 0.435 & $\mathbf{0 . 9 1 1}$ & & & & \\
RC & 3 & $3.74(0.75)$ & 0.697 & 0.535 & $\mathbf{0 . 8 7 8}$ & & & \\
SC & 3 & $3.79(0.70)$ & 0.569 & 0.590 & 0.636 & $\mathbf{0 . 9 0 8}$ & & \\
TKS & 4 & $3.34(0.86)$ & 0.399 & 0.846 & 0.497 & 0.555 & $\mathbf{0 . 9 1 8}$ & \\
WB & 8 & $3.66(0.73)$ & 0.626 & 0.547 & 0.687 & 0.636 & 0.477 & $\mathbf{0 . 8 1 4}$ \\
\hline
\end{tabular}

Note 1: Diagonal bold letters are the square roots of AVE.

\section{Table 6}

Cross Loadings of Each Construct

\begin{tabular}{lllllll}
\hline & CC & EKS & RC & SC & WB & TKS \\
CC1 & $\mathbf{0 . 8 3 8}$ & 0.407 & 0.680 & 0.510 & 0.584 & 0.395 \\
CC2 & $\mathbf{0 . 8 3 9}$ & 0.252 & 0.498 & 0.428 & 0.458 & 0.212 \\
CC3 & $\mathbf{0 . 8 4 5}$ & 0.406 & 0.551 & 0.491 & 0.515 & 0.382 \\
EKS1 & 0.408 & $\mathbf{0 . 9 2 2}$ & 0.523 & 0.500 & 0.480 & 0.732 \\
EKS2 & 0.378 & $\mathbf{0 . 9 2 5}$ & 0.507 & 0.518 & 0.415 & 0.760 \\
EKS3 & 0.369 & $\mathbf{0 . 9 2 7}$ & 0.466 & 0.503 & 0.456 & 0.747 \\
EKS4 & 0.425 & $\mathbf{0 . 8 6 8}$ & 0.454 & 0.617 & 0.460 & 0.835 \\
RC1 & 0.613 & 0.464 & $\mathbf{0 . 8 6 0}$ & 0.566 & 0.506 & 0.394 \\
RC2 & 0.672 & 0.503 & $\mathbf{0 . 9 0 8}$ & 0.602 & 0.635 & 0.488 \\
RC3 & 0.543 & 0.439 & $\mathbf{0 . 8 6 5}$ & 0.501 & 0.472 & 0.420 \\
SC1 & 0.516 & 0.509 & 0.596 & $\mathbf{0 . 9 2 2}$ & 0.574 & 0.446 \\
SC2 & 0.546 & 0.537 & 0.597 & $\mathbf{0 . 9 4 1}$ & 0.566 & 0.508 \\
SC3 & 0.499 & 0.559 & 0.540 & $\mathbf{0 . 8 6 1}$ & 0.532 & 0.552 \\
WB3 & 0.617 & 0.468 & 0.663 & 0.525 & $\mathbf{0 . 7 7 8}$ & 0.414 \\
\hline
\end{tabular}




\begin{tabular}{lllllll}
\hline WB4 & 0.555 & 0.499 & 0.565 & 0.494 & $\mathbf{0 . 8 3 9}$ & 0.436 \\
WB5 & 0.492 & 0.418 & 0.499 & 0.492 & $\mathbf{0 . 8 3 9}$ & 0.393 \\
WB6 & 0.547 & 0.463 & 0.528 & 0.520 & $\mathbf{0 . 8 9 0}$ & 0.392 \\
WB7 & 0.539 & 0.388 & 0.534 & 0.569 & $\mathbf{0 . 8 7 3}$ & 0.345 \\
WB8 & 0.548 & 0.420 & 0.541 & 0.505 & $\mathbf{0 . 7 9 5}$ & 0.337 \\
TKS1 & 0.399 & 0.804 & 0.475 & 0.572 & 0.458 & $\mathbf{0 . 9 2 8}$ \\
TKS2 & 0.364 & 0.723 & 0.437 & 0.514 & 0.392 & $\mathbf{0 . 9 0 8}$ \\
TKS3 & 0.372 & 0.811 & 0.4605 & 0.484 & 0.370 & $\mathbf{0 . 9 0 5}$ \\
TKS4 & 0.358 & 0.766 & 0.4509 & 0.463 & 0.364 & $\mathbf{0 . 9 3 1}$ \\
\hline
\end{tabular}

Note 1: CC=Cognitive Capital, EKS=Explicit Knowledge Sharing, RC=Rational Capital, $S C=$ Structural Capital, $W B=$ the Sense of Well-being, TKS=Tacit Knowledge Sharing.

Note 2: Diagonal bold letters are the cross loading of each construct.

\subsection{Structural Model}

With the measurement model sufficiently validated, all the proposed hypotheses of the research are further demonstrated by analysing the structural model. Meanwhile, in order to evaluate the significance of the path coefficients, a bootstrapping technique, as recommended by Chin (1998b), was used in this study as a resampling method with 500 resamples being taken. As shown in Fig. 2, the analytic results reveal that $\boldsymbol{H 1}, \mathrm{H} 2$ and $\mathbf{H 3}$, which predicted that shared goals (cognitive capital), trust (relational capital), social network ties (structural capital) would positively affect employees' sense of well-being, are supported $(\boldsymbol{H} 1, \beta=0.327, \mathrm{p}<0.001 ; \boldsymbol{H} 2, \beta=0.308, \mathrm{p}<0.01 ; \boldsymbol{H} 3$, $\beta=0.261, \mathrm{p}<0.001)$. In terms of the relationships between employees' sense of well-being and their tacit knowledge-sharing behaviour, and employees' sense of well-being and their explicit knowledge-sharing behaviour, the path coefficient statistics provided in Fig. 2 (i.e. 0.504 and 0.188 ) are both positively significant $(\mathrm{P}=<0.001)$ and therefore support $\mathrm{H4}$ and H5. Moreover, H6, which posited that employees' tacit knowledge-sharing behaviour is strongly associated with their explicit knowledge-sharing behaviour, is also supported $(\beta=0.752, \mathrm{p}=<0.001)$. 


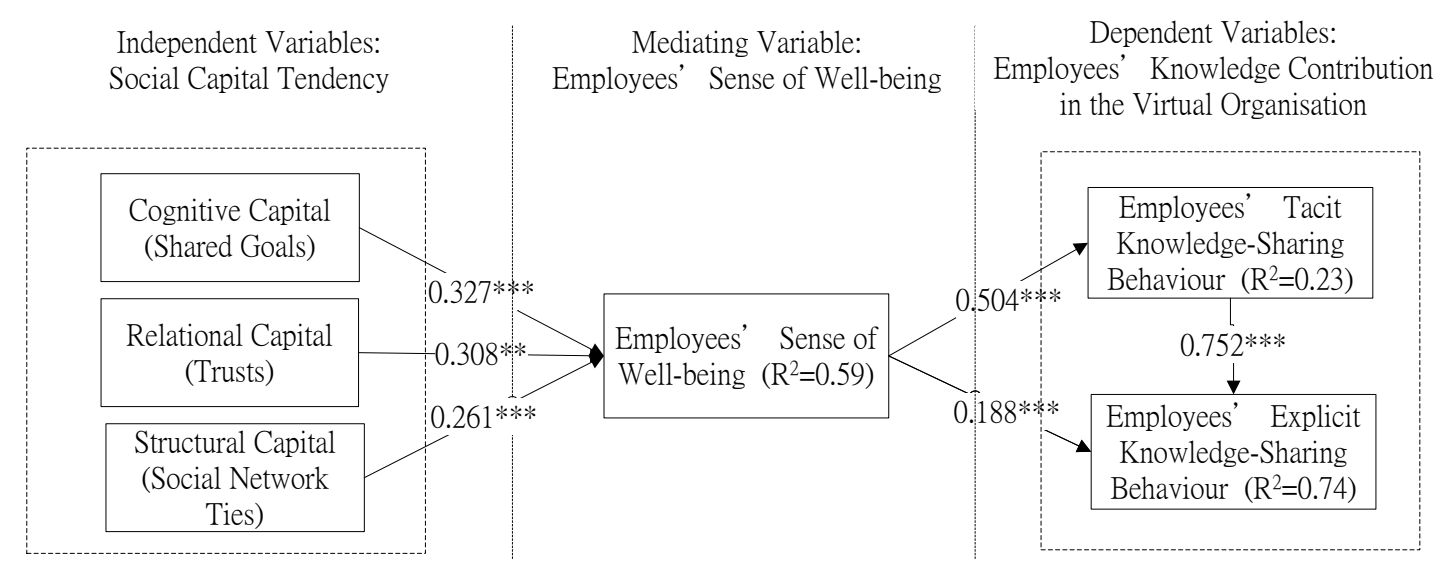

Fig. 2. PLS Analysis of Direct Effects

Note 1: ${ }^{*} p$-value $<0.05(t>1.96) ;{ }^{* *} p$-value $<0.01(t>2.58)$; ${ }^{* * *} p$-value $<0.001(t>3.29)$.

\subsection{The Sense of Well-being as a Mediating Effect}

Meanwhile, in order to deeply comprehend in depth the mediating effect of employees' sense of well-being on the relationship between social capital tendency and employees' tacit and explicit knowledge-sharing behaviour in the virtual organisation, this research chose to adopt a three-step method to analyse the mediating effect mentioned by Baron and Kenny (1986). As shown in Table 7 below, employees' sense of well-being has a partial mediating effect on shared goals and both employees' tacit and explicit knowledge-sharing behaviour. Furthermore, in terms of the impact of the mediating variable of individuals' feeling of well-being on the relationship between trust and both employees' tacit and explicit knowledge-sharing behaviour, the results also show a partially mediating effect. Moreover, employees' sense of well-being has a positively partial mediating impact on the relationship between social network ties and both their tacit and explicit knowledge-sharing behaviour. This research also provides comparisons of the hypothesised fully-mediating, non-mediating and partially mediating models (see Table 8). The results show that our research model (upper left) has more explanatory power (74\%) with regard to employees' explicit knowledge-sharing behaviour by using ICT than the other three listed models. Results confirm that the proposed hypotheses of this research are accepted.

\section{Table 7}

Results of Testing of the Mediating Effect

\begin{tabular}{|c|c|c|c|c|c|c|c|}
\hline \multicolumn{8}{|c|}{ Coefficient in Regressions } \\
\hline \multirow[t]{2}{*}{ IV } & \multirow[t]{2}{*}{ M } & \multirow[t]{2}{*}{ DV } & \multirow[t]{2}{*}{$\mathrm{IV} \rightarrow \mathrm{DV}$} & \multirow[t]{2}{*}{$\mathrm{IV} \rightarrow \mathrm{M}$} & $\mathrm{IV}+\mathrm{M} \rightarrow \mathrm{D}$ & & Mediating \\
\hline & & & & & $\mathrm{IV} \rightarrow \mathrm{DV}$ & $M \rightarrow D V$ & \\
\hline
\end{tabular}




\begin{tabular}{llllllll}
\hline CC & WB & EKS & $0.441^{* * *}$ & $0.624^{* * *}$ & $0.208^{* *}$ & $0.369^{* * *}$ & Partial \\
RC & WB & EKS & $0.536^{* * *}$ & $0.622^{* * *}$ & $0.368^{* * *}$ & $0.272^{* * *}$ & Partial \\
SC & WB & EKS & $0.594^{* * *}$ & $0.500^{* * *}$ & $0.457^{* * *}$ & $0.220^{* * *}$ & Partial \\
CC & WB & TKS & $0.417^{* * *}$ & $0.624^{* * *}$ & $0.237^{*}$ & $0.287^{* *}$ & Partial \\
RC & WB & TKS & $0.561^{* * *}$ & $0.622^{* * *}$ & $0.370^{* * *}$ & $0.207^{*}$ & Partial \\
SC & WB & TKS & $0.497^{* * *}$ & $0.500^{* * *}$ & $0.470^{* * *}$ & $0.148^{*}$ & Partial \\
\hline
\end{tabular}

Note 1: *p-value $<0.05 ; * *$-value $<0.01 ; * * * p$-value $<0.001$.

Note 2: IV=Independent Variable, $M=$ Mediator, $D V=$ Dependent Variable, $C C=C o g n i t i v e$ Capital, $R C=$ Relational Capital, SC=Structural Capital, WB=Well-being, EKS=Explicit Knowledge-sharing, TKS=Tacit Knowledge-sharing .

Note 3: Three-step method for estimating mediating effects is suggested by Baron and Kenny (1986). The process of testing mediating effects is organised as follows:

Step 1: IV $\rightarrow D V$ is significant.

Step 2: $I V \rightarrow M$ is significant.

Step 3: $I V+M \rightarrow D V$

1) When $M$ is significant but $I V$ is not significant, $M$ has a full mediating effect.

2) When both $M$ and IV are significant, $M$ has a partial mediating effect.

Table 8

Results of SEM Analysis

\begin{tabular}{llllll}
\hline \multicolumn{2}{l}{ Hypothesised Model } & \multicolumn{5}{l}{ Non-mediating Model } \\
\hline Path from & Path to & Path coefficient & Path from & Path to & Path coefficient \\
CC & WB & $0.327^{* * *}$ & CC & TKS & 0.029 \\
RC & WB & $0.308^{* *}$ & RC & TKS & $0.221^{*}$ \\
SC & WB & $0.261^{* * *}$ & SC & TKS & $0.402^{* * *}$ \\
WB & TKS & $0.504^{* * *}$ & CC & EKS & 0.025 \\
WB & EKS & $0.188^{* * *}$ & RC & EKS & $0.254^{*}$ \\
TKS & EKS (R $\left.{ }^{2}=74 \%\right)$ & $0.752^{* * *}$ & SC & EKS $\left(\mathrm{R}^{2}=39 \%\right)$ & $0.416^{* * *}$ \\
Partially Mediating Model I & & Partially Mediating Model II & \\
CC & WB & $0.296^{* *}$ & CC & TKS & 0.029 \\
RC & WB & $0.211^{*}$ & RC & TKS & $0.223^{*}$ \\
SC & WB & $0.304^{* * *}$ & SC & TKS & $0.399^{* * *}$ \\
WB & EKS (R $\left.{ }^{2}=34 \%\right)$ & $0.499^{* * *}$ & CC & EKS & 0.004 \\
& & & RC & EKS & 0.090 \\
& & & SC & EKS & 0.128 \\
& & & TKS & EKS $\left(\mathrm{R}^{2}=68 \%\right)$ & $0.731^{* * *}$ \\
\hline
\end{tabular}

Note 1: *p-value $<0.05 ;{ }^{* *} p$-value $<0.01 ;{ }^{* * *}$-value $<0.001$.

Note 2: $C C=$ Cognitive Capital, $R C=$ Relational Capital, $S C=$ Structural Capital, 
WB=Well-being, EKS=Explicit Knowledge-sharing, TKS=Tacit Knowledge-sharing .

Meanwhile, 59\% of the variance in employees' sense of well-being was explained while $23 \%$ of the variance in their tacit knowledge-sharing behaviour was explained. Moreover, it can be seen that $74 \%$ of the variance in employees' explicit knowledge-sharing behaviour was explained.

\subsection{One-way ANOVA}

To further comprehend employees' perspectives of these companies within the virtual organisation in terms of each construct of the research, a one-way ANOVA test was chosen to compare the three categories. First, regarding the four companies of the virtual organisation, the analytic results showed that there was no statistical difference among each company's employees within the virtual organisation, except in terms of employees' sense of well-being. According to the results of the Scheffe post hoc test, the mean of employees' sense of well-being for company 4 (Rural Farmers' Association) was significantly higher than that of company 1 (NTIFO). This might imply that, although employees worked together in the virtual organisation, they still had different feelings about well-being because of coming from the mixed organisational culture environment of the virtual organisation. Then, in terms of age, with the exception of tacit and explicit knowledge sharing, the research found no statistical difference among employees in different age groups. The results showed that, compared with employees aged 26-30, employees aged 46-50 had a greater willingness to share their explicit and tacit knowledge in the virtual organisation. Thirdly, no statistical difference was found for each construct among employees with different working years. Hence, the number of years of employees' work experience had no significant impact on the research outcome.

\section{Theoretical Implications}

The theoretical contributions of this study are three-fold. First, in the light of the lack of prior relevant research, the theoretical model built by this study provides a more comprehensive understanding of the mediating effect of employees' feeling of well-being on the relationships between social capital tendency and both employees' tacit and explicit knowledge-sharing behaviour using ICTs in a more complex context of a virtual organisation. This proposed model adds to the existing body of research concerning employees' knowledge-sharing behaviour in an organisation, especially a virtual organisation. 
The second contribution of this research is to investigate the in-depth gaps between social capital tendency and employees' knowledge-sharing behaviour in a virtual organisation. Although social capital theory has been used previously to shed light on a huge range of social behaviours, few studies have been conducted into employees' knowledge-sharing behaviour in the more complex context of a virtual organisation. Our results reveal that the social capital tendency of employees is relatively weakly or insignificantly associated with both their tacit and explicit knowledge-sharing behaviour in the virtual organisation; however, increasing employees' sense of well-being can successfully form a bridge that effectively connects social capital tendency and employees' knowledge-sharing behaviour through using ICTs. Moreover, as noted in Fig. 2, employees' sense of well-being was found to have a more positive effect on tacit knowledge-sharing behaviour $(\beta=0.504)$ than on explicit knowledge-sharing behaviour ( $\beta=0.188$ ). This important finding is worth noting since, as suggested by Alwis and Hartmann (2008), competitive advantage will be significantly improved if an organisation attaches importance to employees' tacit knowledge.

The third contribution of this research highlights the importance of converting employees' tacit knowledge into explicit knowledge in the more complex context of a virtual organisation. Externalising the conversion of knowledge can be seen as part of the process of creating new knowledge; this is triggered through dialogue concerning their experiences among employees (Nonaka, 1994). This research finding strengthens the importance of externalising the knowledge conversion process as this holds the key to creating new explicit knowledge from a tacit form in the virtual organisation.

\section{Practical Implications}

This study is one of the first to provide empirical evidence concerning the relationships among social capital tendency, employees' sense of well-being and knowledge-sharing behaviour in the virtual organisation. The new findings from this work may convince managers or researchers of virtual organisations to attach significant importance to employees' knowledge-sharing behaviour in such an organisation with a view to enhancing the organisation's competitive advantage and ultimate goals. Several practical implications are provided and organised as follows.

First, our results reveal that trust (relational capital) has a significantly positive impact 
on employees' sense of well-being. Hence, employees of the virtual organisation are likely to be able to feel a greater sense of well-being if the organisation can develop a trust-based social network. It is also interesting to note that social network ties (structural capital) positively influence employees' sense of well-being in the virtual organisation. This suggests that encouraging more compact relationships among employees could be an important component that would make them feel a greater sense of well-being in the virtual organisation. The analytic results also show that employees experience a positive sense of well-being if they have consensus on the shared goals (cognitive capital) of the virtual organisation. However, our results show that the social capital tendency of employees is only weakly or even insignificantly associated with both their tacit and explicit knowledge-sharing behaviour in the virtual organisation (see Table 8). This may be due to the nature of most virtual organisations whose members tend to have short-term cooperative relationships. To ease this situation and increase the social support offered by co-workers, managers in a virtual organisation should encourage their employees to engage in longer-lasting social relationships (Zhang et al., 2014) and should consider establishing appropriate ICT which will more closely suit their online social structure (Zhang, Vogel, \& Zhou, 2012).

Secondly, and more importantly, our results show that employees' feeling of well-being has a significantly positive impact on both their tacit and explicit knowledge-sharing behaviour in the virtual organisation. It seems that a key aspect in employees' willingness to share knowledge through ICTs is their sense of well-being in the virtual organisation. In other words, employees who demonstrate psychological elements concerning well-being, (e.g. higher levels of positive emotions and satisfaction with life, and lower levels of negative ones (Diener et al., 2002); better engagement with the surrounding environment (Diener \& Seligman, 2004; Chen, Zhang, \& Vogel, 2011); and a willingness to help others (Boehm and Lyubomirsky (2008)) will have a greater willingness to share knowledge than their peers with lower levels of well-being.

Third, regarding the mediating effect of employees' feeling of well-being on the relationship between social capital tendency and both explicit and tacit knowledge-sharing behaviour, our results show that employees' feeling of well-being plays a partial mediating role in the relationship between their social capital tendency (e.g. achieving shared goals, trusting others, having compact social network ties) and their tacit and explicit knowledge-sharing behaviour (see Table 7). The findings of the study indicate that improving the social values underlying compact mutuality, trust 
and shared goals among employees of a virtual organisation, through employees' sense of well-being, can offer enormous benefits for employees' knowledge-sharing behaviour via ICTs; this ultimately improves the organisation's competitive advantage. Since employees receive more social support from their colleagues, they then tend to use more cooperative approaches, such as sharing knowledge, when interacting with others.

In sum, despite our evidence that the virtual organisation's employees who experience a greater sense of well-being seem to enjoy sharing knowledge more than others with a lesser one, it is necessary to recognise that employees' sense of well-being is not the only factor that can lead them to share their knowledge. Likewise, negative emotions or a lower sense of well-being cannot be ignored. This is because each type of emotion seemingly serves its own purpose and has its own effects. Our conclusion is that a greater sense of well-being is particularly well situated to encourage employees' knowledge-sharing behaviour in a virtual organisation. Hence, managers of virtual organisations may need to take employees' sense of well-being into account while encouraging and improving the positive development of employees' social capital tendency in the more complex context of the virtual organisation.

\section{Future Research}

This study provides new insights into how employees' sense of well-being mediates the relationship between their social capital tendency and both tacit and explicit knowledge-sharing behaviour within the more complex context of the virtual organisation of Taiwanese NGOs. However, some shortcomings of this study still need to be further explored in the future. First, considering that the sense of well-being is a broad and complex construct, the scale used in this study may be insufficient in reflecting employees' entire sense of well-being in the complex context of the virtual organisation. Moreover, a virtual organisation consists of numerous companies whose employees work in different areas based on different types of organisational culture. This may also influence their willingness to share knowledge. As well as being aware of the importance of the impact of multi-national cultures on knowledge-sharing behaviour (Zhang, Chen, Vogel, Yuan \& Guo, 2010; Zhang et al., 2014), the differences in Western and Chinese cultures should be considered in future research. Consequently, to gain greater insight into more in-depth factors concerning individuals' knowledge-sharing behaviour in the virtual organisation, more longitudinal studies and the comparison of cultural diversity might be conducted in future research. 


\section{References}

Alge, B. J., Wiethoff, C., \& Klein, H. J. (2003). When does the medium matter: Knowledge building experiences and opportunities in decision making teams. Organizational Behavior and Human Decision Processes, 91(1), 26-37.

Alwis, R.S. \& Hartmann, E. (2008). The use of tacit knowledge within innovative companies: knowledge management in innovative enterprises. Journal of Knowledge Management, 12 (1), 133-147.

Argyle, M., Martin, M., \& Crossland, J. (1989). Happiness as a function of personality and social encounters. In J. P. Forgas, \& J. M. Innes (Eds.), Recent advances in Social Psychology: An international Perspective (pp. 189-203). North-Holland: Elsevier.

Barclay, D., Thompson, R., \& Higgins, C. (1995). The partial least squares (PLS) approach to causal modeling: Personal computer adoption and use an illustration. Technology Studies, 22(2), 285-309.

Baron, N.S., \& Kenney, D.A. (1986). The moderator - mediator variable distinction in social psychological research: Conceptual, strategic, and statistical considerations. Journal of Personality and Social Psychology, 51(6), 1173-1182.

Blažun, H., Saranto, K., \& Rissanen, S. (2012). Impact of computer training courses on reduction of loneliness of older people in Finland and Slovenia. Computers in Human Behavior, 28(4), 1202-1212.

Boehm, J.K., \& Lyubomirsky, S. (2008). Does happiness promote career success?. Journal of Career Assessment, 16, 101-116.

Bourdieu, P. (1986). The forms of capital. In J. G. Richardson (ed.), Handbook of theory and research for the sociology of education (pp. 241-258). New York: Greenwood.

Carr, A. (2004). Positive psychology: the science of happiness and human strengths. London: Routledge.

Chen, Z.J., Zhang, X., \& Vogel, D. (2011). Exploring the underlying processes between conflict and knowledge sharing: A work engagement perspective. Journal of Applied Social Psychology, 41(5), 1005-1033.

Chi, H.K., Yeh, H.R., \& Yu, C.H. (2008). The effects of transformation leadership, organizational culture, job satisfaction on the organizational performance in the non-profit organizations. The Journal of Global Business Management, 4(1), 129-137.

Chin, W.W. (1998a). Issues and opinion on structural equation modeling. MIS 
Quarterly, 22(1), vii-xvi.

Chin, W.W. (1998b). The partial least squares approach to structural equation modeling. In Marcoulides, G.A. (Ed.), Modern Methods for Business Research (pp. 295-336). Mahwah, NJ: Lawrence Brlbaum Associates.

Chin, W.W., Marcolin, B.L., \& Newsted, P.R. (2003). A partial least squares latent variable modeling approach for measuring interaction effects: Results from a Monte Carlo simulation study and an electronic mail emotion/adoption study. Information Systems Research, 14(2), 189-217.

Chiu, C.M., Hsu, M.H., \& Wang, E.T. G. (2006). Understanding knowledge sharing in virtual communities: An integration of social capital and social cognitive theories. Decision Support Systems, 42(3), 1872-1888.

Chow, W.S., \& Chan, L.S. (2008). Social network, social trust and shared goals in organisational knowledge sharing. Information \& Management, 45(7), 458-465.

Cohn, M.A., Fredrickson, B.L., Brown, S.L., Mikels, J.A., \& Conway, A.M. (2009). Happiness unpacked: Positive emotions increase life satisfaction by building resilience. Emotion, 9(3), 361-368.

Curran, P. J., West, S. G., \& Finch, J. F. (1996). The robustness of test statistics to nonnormality and specification error in confirmatory factor analysis. Psychological Methods, 1(1), 16-29.

Dhanaraj, C., Lyles, M.A., Steensma, H.K., \& Tihanyi, L. (2004). Managing tacit and explicit knowledge transfer in IJVs: The role of relational embeddedness and the impact on performance. Journal of International Business Studies, 35(5), 428-442.

Diener, E., \& Biswas-Diener, R. (2002). Will money increase subjective well-being? A literature review and guide to needed research. Social Indicators Research, 57(2), 119-169.

Diener, E., Lucas, R.E., \& Oishi, S. (2002). Subjective well-being: The science of happiness and life satisfaction. In C.R. Snyder, \& S.J. Lopez (ed.), Handbook of Positive Psychology (pp. 63-73). Oxford: Oxford University Press.

Diener, E., \& Seligman, M.E.P. (2004). Toward an economy of well-being. Psychological Science in the Public Interest, 5(1), 1-31.

Diener, E., Suh, E.M., Lucas, R.E., \& Smith, H.L. (1999). Subjective well-being: Three decades of progress. Psychological Bulletin, 125(2), 276-302.

Dodge, R., Daly, A., Huyton, J., \& Sanders, L. (2012). The challenge of defining wellbeing. International Journal of Wellbeing. 2(3), 222-235.

Drucker, P. F. (1990). Managing the non-profit organizations: Practices and principles. New York: Harper Collins Publishers.

Endres, M.L., Endres, S.P., Chowdhury S.K., \& Alam, I. (2007). Tacit knowledge 
sharing, self-efficacytheory, and application to the open source community. Journal of knowledge management, 11(3), 92-103.

Fornell, C., \& Larcker, D. (1981). Evaluating structural equation models with unobservable variables and measurement error. Journal of marketing research, 18(1), 39-50.

George, J. M. (1991). State or trait: Effects of positive mood on prosocial behaviors at work, Journal of Applied Psychology, 76(2), 299-307

Goldman, L., Nagel, R.L., \& Preiss, K. (1995). Agile competitors and virtual organisation - Strategies for Enriching the Customer. New York: Van Nostrand Reinhold.

Goswami, H. (2012). Social relationships and children's subjective well-being. Social Indicators Research, 107(3), 575-588.

Hau, Y.S., Kim, B., Lee, H., \& Kim, Y.G. (2013). The effects of individual motivations and social capital on employees' tacit and explicit knowledge sharing intentions. International Journal of Information Management, 33(2), 356-366.

He, W., Qiao, Q., \& Wei, K. K. (2009). Social relationship and its role in knowledge management system usage. Information and Management, 46(3), 175-180.

Helliwell, J.F., \& Putnam, R.D. (2004). The social context of well-being. Philosophical Transactions: Biological Sciences, 359(1449), 1435-1446.

Helliwell, J.F., \& Huang, H. (2011). Well-being and trust in the workplace. Journal of Happiness Studies, 12(5), 747-767.

Helliwell, J. F., \& Wang, S. (2011). Trust and wellbeing. International Journal of Wellbeing, 1(1), 42-78.

Henry, P. (2004). Hope, hopelessness, and coping: A framework for class-distinctive cognitive capital. Psychology \& Marketing, 21(5), 375-403.

Hills, P. \& Argyle, M. (2002). The Oxford Happiness Questionnaire: a compact scale for measurement of psychological well-being. Personality and Individual Differences, 33(7), 1073-1082.

Holste, J.S., \& Fields, D. (2010). Trust and tacit knowledge sharing and use. Journal of Knowledge Management, 14(1), 128-140.

Huang, J.L. (1992). Adjustment of Taiwanese agricultural financial system - based on Financial liberalization and internationalization. Taiwan Community Financial Journal, 26, 145-173.

Iverson, R. D., Olekalns, M., \& Erwin, P. J. (1998). Affectivity, organizational stressors, and absenteeism: A causal model of burnout and its consequences. Journal of Vocational Behavior, 52(1), 1-23.

Jacobs, J. (1965). The death and life of great American cities. London: Penguin. 
Joseph, S., \& Lewis, C. A. (1998). The depression-happiness scale: Reliability and validity of a bipolar self-report scale. Journal of Clinical Psychology, 54(4), 537-544.

Kahneman, D., \& Riis J. (2005). Living, and thinking about it: Two perspectives on life. In Huppert, F.A., Baylis, N. and Keverne, B. (Eds.), The science of well-being (pp. 285-304). Oxford: Oxford University Press.

Kankanhalli, A., Tan, B.C.Y., \& Wei, K.K. (2005). Contributing knowledge to electronic knowledge repositories: An empirical investigation. MIS Quarterly, 29(1), 113-143.

Keyes, C.L.M. (1998). Social well-being. Social psychology quarterly, 61(2), 121-140.

Lau, M., \& Li, W. (2011). The extent of family and school social capital promoting positive subjective well-being among primary school children in Shenzhen, China. Children and Youth Services Review, 33(9), 1573-1582.

Locke, E.A., \& Latham, G.P. (2006). New directions in goal-setting theory. Current Directions in Psychological Science, 15(5), 265-268.

Nahapiet, J., \& Ghoshal, S. (1998). Social capital, intellectual capital, and the organizational advantage. The Academy of Management Review, 23(2), 242-266.

Nonaka, I. (1991). The knowledge-creating company. Harvard Business Review, 69(6), 96-104.

Nonaka, I. (1994). A dynamic theory of organisational knowledge creation. Organisation Science, 5(1), 14-37.

Nonaka, I., \& Krog, G.V. (2009). Tacit knowledge and knowledge conversion: Controversy and advancement in organisational knowledge creation theory. Organisation Science, 20(3), 635-652.

Nonaka, I., \& Takeuchi, H. (1995). The knowledge creating company. New York: Oxford University Press.

Nunnally, J.C. (1978). Psychometric Theory. New York: McGraw-Hill.

Podsakoff, P.M., MacKenzie, S.B., Lee, J.Y., \& Podsakoff, N.P. (2003). Common method biases in behavioral research: A critical review of the literature and recommended remedies. Journal of Applied Psychology, 88(5), 879-903.

Podsakoff, P.M., \& Organ, D.W. (1986). Self-reports in organizational research: Problems and prospects. Journal of Management, 12(4), 531-544.

Rai, A., Patnayakuni, R., \& Seth, N. (2006). Firm performance impacts of digitally enabled supply chain integration capabilities. MIS Quarterly, 30(2), 225-246.

Reychav, I., \& Weisberg, J. (2009). Paved with good intentions: Discrepancies in Knowledge. International Journal of Information Management, 29(5), 353-361. 
Robbins, M., Francis, L. J., \& Edwards, B. (2010). Happiness as stable extraversion: Internal consistency reliability and construct validity of the oxford happiness questionnaire among undergraduate students. Current Psychology, 29(2), 89-94.

Russell, J.E.A. (2008). Promoting subjective well-being at work. Journal of Career Assessment, 16(1), 117-131.

Ryan, R.M., \& Deci, E.L. (2001). On happiness and human potentials: A review of research on hedonic and eudaimonic well-being. Annual Review of Psychology, 52, 141-166.

Ryff, C.D. (1989). Happiness is everything, or is it? Explorations on the meaning of psychological well-being. Journal of Personality and Social Psychology, 57(6), 1069-1081.

Ryff, C.D., \& Singer, B.H. (2008). Know thyself and become what you are: A eudaimonic approach to psychological well-being. Journal of Happiness Studies, 9(1), 13-39.

Ryff, C.D. \& Keyes, C.L. (1995). The structure of psychological well-being revisited. Journal of Personality and Social Psychology, 69 (4), 719-727.

Sarracino, F. (2010). Social capital and subjective well-being trends: comparing 11 western European countries. The Journal of Socio-Economics, 39 (4), 482-517.

Saari, L. M., \& Judge, T. A. (2004). Employee attitudes and job satisfaction. Human Resource Management, 43(4), 395-407.

Schwarz, N., \& Clore, G. L. (2007). Feelings and phenomenological experiences. In E.T. Higgins, \& A.W. Kruglanski, (Eds.), Social psychology: handbook of basic principles (pp. 385-407). New York: Guilford Press.

Seligman, M.E.P. \& Csikszentmihalyi, M. (2000). Positive psychology: an introduction. American Psychologist, 55(1), 5-14.

Shao, Z., Feng, Y., \& Liu, L (2012). The mediating effect of organizational culture and knowledge sharing on transformational leadership and enterprise resource planning systems success: An empirical study in China. Computers in Human Behavior, 28(6), 2400-2413.

Wasko, M.M., \& Faraj, S. (2005). Why should I share? Examining social capital and knowledge contribution in electronic networks of practice. MIS Quarterly, 29(1), 35-57.

Yamaguchi, A. (2013). Impact of social capital on the psychological well-being of adolescents, International Journal of Psychological Studies, 5(2), 100-109.

Yip, W., Subramanian, S. V., Mitchell, A. D., Lee, T. S., Wang, J., \& Kawachi, I. (2007). Does social capital enhance health and well-being? Evidence from rural China. Social Science \& Medicine, 64(1), 35-49. 
Zhang, X., Chen, Z., Vogel, D., Yuan, M., \& Guo, C. (2010). Knowledge sharing reward dynamics in knowledge management systems: Game theory-based empirical validation. Human Factors and Ergonomics in Manufacturing, 20(2), 101-121.

Zhang, X., de Pablos, P.O., \& Xu, Q (2014). Culture effects on the knowledge sharing in multi-national virtual classes: A mixed method. Computers in Human Behavior, 31, 491-498.

Zhang, X., de Pablos, P., \& Zhang, Y. (2012). The Relationship between Incentives, Explicit and Tacit Knowledge Contribution in Online Engineering Education Project. International Journal of Engineering Education, 28, 1341-1346.

Zhang, X., de Pablos, P., \& Zhou., Z. (2013). Effect of Knowledge Sharing Visibility on incentive-based relationship in Electronic Knowledge Management Systems: An Empirical Investigation. Computers in Human Behavior, 29, 307-313.

Zhang, X., Vogel, D., \& Zhou, Z. (2012). Effects of Information Technologies, Department Characteristics and Individual Roles on Improving Knowledge Sharing Visibility: A Qualitative Case Study. Behaviour \& Information Technology, 31(11), 1117-1131.

\section{Appendix A. Measurement Items}

\section{Social Capital Theory}

Social Structural Capital (Social Network ties): The degree to which an employee has contact with his/her virtual organisational members (Chow \& Chan, 2008; Chiu et al., 2006; Hau et al., 2013).

SC1) I am not very close to my virtual organisational colleagues (-).

SC2) I have a very good relationship with my virtual organisational colleagues.

SC3) I do not spend a lot of time interacting with employees in the virtual organisation (-).

Social Relational Capital (Trust): The degree to which an employee believes that other colleagues are reliable and trustworthy in the virtual organisation (Chow \& Chan, 2008; Chiu et al., 2006; Hau et al., 2013).

RC1) I don't trust that my virtual organisational colleagues are worthy to rely on (-).

RC2) I know my virtual organisational members will try to help me when I get into difficulties.

RC3) I cannot rely on my virtual organisational members to make my job easier (-).

Social Cognitive Capital (Goals): The degree to which the virtual organisation's members are involved with shared goals (Chiu et al., 2006; Chow \& Chan, 2008; Hau et al., 2013). 
CC1) There is considerable consensus among my virtual organisational colleagues about what is important at work.

CC2) My virtual organisational colleagues are not enthusiastic about achieving goals and missions of the organisation (-).

CC3) My virtual organisational colleagues and I always share the same ambitions and goals at work.

Employees' Sense of Well-being: The degree to which an employee feels a sense of well-being in the virtual organisation. (Oxford Happiness Questionnaire Short-Form, Hills \& Argyle, 2002)

WB1) I don't feel particularly pleased with the way I am (-).

WB2) I feel that life is very rewarding.

WB3) I am well satisfied about everything in my life.

WB4) I don't think I look attractive (-).

WB5) I find beauty in some things.

WB6) I can fit in everything I want to.

WB7) I feel fully mentally alert.

WB8) I do not have particularly happy memories of the past (-).

Explicit Knowledge Sharing: The extent to which an employee has the willingness to share his/her explicit knowledge in the virtual organisation (Chow \& Chan, 2008; Shao et al., 2012; Hau et al., 2013).

EKS1) I am glad to share my work reports on the IT systems with other employees in the virtual organisation.

EKS2) I do not like to provide my personal manuals on the IT systems with other employees in the virtual organisation (-).

EKS3) I am pleased to share related official documents on the IT systems with other employees of the virtual organisation.

EKS4) I will not share multimedia files such as media, context, picture or video on the IT systems with colleagues of my organisation (-).

Tacit Knowledge Sharing: The extent to which an employee has the willingness to share his/her tacit knowledge in the virtual organisation (Chow \& Chan, 2008; Shao et al., 2012; Hau et al., 2013).

TKS1) I always share my experience or know-how from work on the IT systems with my virtual organisational colleagues.

TKS2) I always share my know-where or know-whom on the IT systems at the request of my virtual organisational colleagues.

TKS3) I do not like to provide my expertise on the IT systems with other employees of this virtual organisation (-).

TKS4) I am not usually actively involved in discussion on complicated issues on the 
IT systems in the virtual organisation (-). 